\title{
National Income and Income Inequality, Family Affluence and Life Satisfaction Among 13 year Old Boys and Girls: A Multilevel Study in 35 Countries
}

\author{
Kate Ann Levin • Torbjorn Torsheim • Wilma Vollebergh • \\ Matthias Richter · Carolyn A. Davies • Christina W. Schnohr • \\ Pernille Due $\cdot$ Candace Currie
}

Accepted: 18 October 2010/Published online: 1 November 2010

(C) The Author(s) 2010. This article is published with open access at Springerlink.com

\begin{abstract}
Adolescence is a critical period where many patterns of health and health behaviour are formed. The objective of this study was to investigate cross-national variation in the relationship between family affluence and adolescent life satisfaction, and the impact of national income and income inequality on this relationship. Data from the 2006 Health Behaviour in School-aged Children: WHO collaborative Study ( $N=58,352$ across 35 countries) were analysed using multilevel linear and logistic regression analyses for outcome measures life satisfaction score and binary high/low life satisfaction. National income and income inequality were associated with aggregated life satisfaction score and prevalence of high life satisfaction. Within-country socioeconomic inequalities in life satisfaction existed even after adjustment for family structure. This relationship was curvilinear and varied cross-nationally. Socioeconomic inequalities were greatest in poor countries and in countries with unequal income distribution. GDP (PPP US\$) and Gini did not explain between country variance in socioeconomic inequalities in life satisfaction. The existence of, and variation in, within-country socioeconomic inequalities in adolescent
\end{abstract}

K. A. Levin $(\bowtie) \cdot$ C. Currie

University of Edinburgh, Edinburgh, UK

e-mail: kate.levin@ed.ac.uk

T. Torsheim

University of Bergen, Bergen, Norway

W. Vollebergh

University of Utrecht, Utrecht, Netherlands

M. Richter

University of Bielefeld, Bielefeld, Germany

C. A. Davies

University of Glasgow, Glasgow, UK

C. W. Schnohr

University of Copenhagen, Copenhagen, Denmark

P. Due

University of Southern Denmark, Copenhagen, Denmark 
life satisfaction highlights the importance of identifying and addressing mediating factors during this life stage.

Keywords Adolescent health · Life satisfaction - National income ·

Socioeconomic inequalities

\section{Introduction}

The World Health Organization (WHO) defines mental well-being as a state in which "the individual realizes his or her own abilities, can cope with the normal stresses of life, can work productively and fruitfully, and is able to make a contribution to his or her community" (Herman et al. 2005). Mental well-being or positive mental health, can be separated into two streams, the eudaimonic stream, the way in which people function in life, and the hedonic stream, the way in which they perceive their life (Keyes 2006). Life satisfaction falls into the hedonic stream. It is a global judgement of one's life and, among adults, is strongly associated with depression, anxiety and suicide (Helliwell 2007; Koivumaa-Honkanen et al. 2001, 2004).

Previous cross-national studies investigated the role of income on the life satisfaction of adults, both at the individual level and the aggregated country level, and found that adult life satisfaction is dependent on an income level which allows for basic needs to be met (Diener et al. 1995; Diener and Biswas-Diener 2002), supported by Maslow's need-gratification model which hypothesises that "degree of basic need gratification is positively correlated with degree of psychological health" (Maslow 1970). Once these basic needs are met, however, further increases in income have less of an impact on life satisfaction. At the individual level, therefore, increasing income has a diminishing effect on well-being (Schyns 2002), while at a country level, the relationship between income and well-being is stronger for poorer countries (Veenhoven 1991), and there is larger cross-national variation in the relationship between life satisfaction and income among developed countries of approximately equal income (Oishi et al. 1999a). The role of individual wealth, therefore, varies according to the level of national income. The value-as-a-moderator theory states that after a certain level of national income, cultural and societal factors such as values and beliefs become more important in predicting life satisfaction (Oishi et al. 1999b).

The effect of within country income inequality on adult life satisfaction has also been investigated. Under the relativist's model it is not income in itself that determines life satisfaction but the comparison of income to one's neighbour (Easterlin 1974), so that a country with a less equal income distribution should result in lower mean subjective wellbeing. Diener et al. (1995) tested this theory and found that the relationship between a country's income inequality and mean well-being became insignificant when country income, individualism or human rights were adjusted for. Di Tella et al. (2003) showed that as well as a country's Gross Domestic Product (GDP) and welfare benefits system, dynamic factors such as change in GDP are also associated with a nation's happiness, in other words during a recession life satisfaction is seen to decrease. Schyns (2002) similarly found that national income was a greater predictor of individual life satisfaction. No equivalent cross-national work on the relationship between national income, income inequality and life satisfaction has been carried out on adolescent samples. From a lifecourse perspective, it is useful to determine whether the patterns observed in previous research in adulthood are also true in adolescence or if whether they emerge later in life, from both the point of view of public health monitoring and intervention design as well as 
sociological and economic understanding of the relationship between income and wellbeing.

There is a general consensus that socioeconomic inequalities exist internationally for many adult and child health outcomes, however, the existence of socioeconomic inequalities in health during adolescence has been the focus of much debate. While some have found no social gradient at this stage of life (West 1997), others have shown socioeconomic inequalities among adolescents to exist for a wide range of health outcomes (Chen et al. 2006; Currie et al. 2008a; Starfield et al. 2002). In their review of studies relating to inequalities in children and young people's health, Chen et al. (2002), showed that inequalities in adolescence depended on the health outcome under study. Spencer (2006) concluded that the existence of socioeconomic inequalities in health depended on the age group, health outcome under investigation and measure of socioeconomic status (SES) used.

Previous studies of adolescent mental health showed association between lower SES and adolescent depression, anxiety, hostility, control and stress (Attar et al. 1994; Chen et al. 2004; Goodman 1999; Gump et al. 1999). Few studies have examined the relationship between life satisfaction and SES. National studies have shown the existence of this association among adolescents in Canada (Burton and Phipps 2008) and the US (Ash and Huebner 2001). The HBSC International Report (Currie et al. 2008b) presents crossnational findings which show, using the Family Affluence Scale (FAS), that socioeconomic inequalities in life satisfaction existed for boys and girls across all countries, with the exception of Greenland. However, as there are obvious economic disadvantages in living in some family structures it is possible that SES is merely a proxy for family structure, known to be related to emotional and physical well-being of children (Attar et al. 1994; Repetti et al. 2002).

Furthermore, as the FAS low, medium and high groups were calculated globally, resulting inequalities in life satisfaction in less wealthy countries such as Turkey, where $70 \%$ of the sample had low FAS compared with the elite $5 \%$ with high FAS, would be far more extreme compared with a country with a more even FAS distribution, such as Portugal. Differences may therefore exist between and within countries, according to national income and income distribution, as well as individual socioeconomic position. This raises the following questions addressed in this study:

1. Is national income or income distribution associated with life satisfaction of young people?

2. Do within-country socioeconomic inequalities in life satisfaction exist for young people after adjustment for family structure?

3. Does the relationship between within-country socioeconomic inequalities and life satisfaction vary by country for young people?

4. Does national income or income distribution affect individual level within-country socioeconomic inequalities in life satisfaction among young people?

\section{Methods}

\subsection{Data and Participants}

The data analysed in this study were collected in the Health Behaviour in School-aged Children (HBSC) WHO collaborative cross national study 2005/2006 (Currie et al. 2008b), 
in which 41 countries/regions participated. The survey is carried out every 4 years with each region/country selecting nationally representative samples of 11,13 and 15 year old children. The primary sampling unit is the school class or whole school where sample frame of classes is not available. A random sample is selected, with some countries stratifying by region, school type (e.g. state versus private school) or geography (e.g. urban versus rural), and others selecting a simple random sample. A total of 204,534 young people took part in the 2005/2006 survey. Response rate for schools was high, above $80 \%$ in the majority of countries. More information regarding how schools were sampled, children recruited, response rates for both schools and children, and the method of data collection used, including the rationale for these methods, is available elsewhere (Currie et al. 2008b).

Of the 41 countries taking part in the 2005/2006 HBSC survey, only 35 were included in the analysis presented in this paper. Malta and Belgium (French) did not collect life satisfaction data. Slovakia was not included due to missing school information. Greenland and Israel were also excluded from analysis due to a high proportion of missing data. For the majority of countries less than $2 \%$ of data were missing. Wales was excluded as country-level data were not available. The 35 countries included in the analysis were: Austria, Belgium (Flemish), Bulgaria, Canada, Croatia, Czech Republic, Denmark, England, Estonia, Finland, France, Germany, Greece, Hungary, Iceland, Ireland, Italy, Latvia, Lithuania, Luxembourg, Netherlands, Norway, Poland, Portugal, Romania, Russian Federation, Scotland, Slovenia, Spain, Sweden, Switzerland, Turkey, TYFR Macedonia, Ukraine, USA. A total of 58,364 13-year old schoolchildren from these countries, were included in the analyses described below.

\subsection{Outcome Measure}

Survey respondents were shown a picture of a ladder and asked: Here is a picture of a ladder-the top of the ladder 10 is the best possible life for you and the bottom is the worst possible life - in general where on the ladder do you feel you stand at the moment? This is an adapted version of the Cantril Ladder (Cantril 1965). A binary measure was also calculated where a score of 6 or more was defined as high life satisfaction and below 6 , as low. A binary measure of life satisfaction "has the advantage of not relying on differences in reported intensity" (Diener and Biswas-Diener, pp. 124) and may be preferred in crossnational analyses due to cultural differences in the interpretation of scale values. Both binary and continuous measures were used in the analysis and the results discussed.

\subsection{Child- Level Explanatory Variables}

In adults, SES is usually measured by income, education or occupation. Adolescents, however, have little economic power themselves, as they normally do not participate in the labour market. Most often, the SES of the father, mother or overall household is the proxy applied to adolescents. While this is achievable in household based surveys where adults are involved, difficulties arise in school-based surveys as young people often do not know their parents' income, education or occupation, resulting in high rates of non-response (Currie et al. 1997; Wardle et al. 2002). Additionally, bias has been reported with greater non-response in low socioeconomic groups (Lien et al. 2001; Wardle et al. 2004). More recent studies of adolescent health have recommended the use of socioeconomic measures that reflect material circumstances over more conventional measures such as parental occupation (Spencer 2006; Emerson et al. 2006). 
The Family Affluence Scale (FAS) (Currie et al. 2008a) is calculated using the following questions: Does your family have a car or van? (no/yes, onelyes, two or more); Do you have your own bedroom to yourself? (no/yes). During the past 12 months, how many times did you travel away on holiday with your family? (not at all/once/twice or more). How many computers (PCs, Macs or laptops) does your family own? (none/one/two/more than two). Responses were combined and standardised using a ridit transformation to give a linear score within each country. The econometric results obtained with the FAS scale are entirely contingent on how the scale is constructed from the individual response items. The method used in this study has been used previously and is recommended to compare the effects of FAS (Torsheim et al. 2004, 2006). Ridit transformations have also been used in other socioeconomic measures (Manor et al. 1997). This continuous measure describes a within-country incremental rise in family affluence within each country having an overall mean score of transformed FAS $=0.5$.

Family structure, a potential confounder of the relationship between family affluence and life satisfaction, was included in the analysis. Previously, Burton and Phipps (2008) included only those from 2-parent families in order to avoid confounding. In the current study in order to maximise the power of the study, children from all family structures were included and family structure was adjusted for in analysis. Survey respondents were given a checklist of people from which they ticked those living in their main or only home. Respondents were coded as living with 'Both parents', a 'Single parent', in a 'Step family' or 'Other'.

\subsection{Country- Level Explanatory Variables}

The Gini coefficient is a measure of income inequality between households within a population, ranging from zero (complete equality) to one (complete inequality), where, hypothetically, one household has all the income. Gross Domestic Product at purchasing power parity (GDP per capita (PPP US\$)) is the value of all goods and services produced within a country in a given year divided by the mid-year population for that year. GDP per capita (PPP US\$) data were those of 2005, while Gini coefficients were calculated from national surveys carried out primarily between 2000 and 2003, as reported in the Human Development 2007/2008 Report (United Nations Development Programme 2008) for all countries with the exception of Scotland, whose figures were obtained from the Scottish Government (Scottish Executive 2006, 2007), Iceland and Luxembourg, for whom the Gini coefficient reported in the Human Development 2005 Report was used instead (United Nations Development Programme 2005).

\subsection{Analyses}

Country-level correlations were run as preliminary analyses between country average life satisfaction and GDP (PPP US\$)/Gini. Multilevel linear regression was carried out, as recommended in the literature when using data of a hierarchical nature and including variables of different levels (Schyns 2002; Oishi et al. 1999a), with continuous outcome measure life satisfaction score, using MLwiN version 2.02 (Rasbash et al. 2004). Running a linear regression with a life satisfaction score as dependent variable implicitly assumes the score can be interpreted as a series of steps with equal distance between each. Ordered logit regressions, for ordinal rather than cardinal measures, may be a preferable method of analysis. However, computationally this was too cumbersome a procedure for a dataset of this size and given the complexity of the models in this study. 
Models were created with 4 levels: country/region, stratum, class and individual. Stratification of the population when sampling differed by country, e.g. by geography or school type, and a stratum level was included in the model to overcome any over- or undersampling of groups caused by within-country sampling designs. The first set of models adjusted for pupil's age, family structure, ridit-transformed FAS score and the square of ridit-transformed FAS, to determine whether there was a relationship between an incremental increase in relative affluence and life satisfaction, and what shape this relationship might take. Including the squared term allows for a non-linear relationship. Ridit-transformed FAS was centred for this analysis to avoid colinearity between the score and its square. Effect sizes for age, sex, family structure and ridit-transformed FAS were tabulated and pseudo-R squared calculated for each model, using 1- [the ratio of unexplained variance to total variance in the dependent variable (i.e. the null model)]. Transformed FAS was then given a random slope to determine if the relationship between FAS and life satisfaction varied between countries. A second set of models were then run including country level data. Interactions were included between transformed FAS and the log of GDP (PPP US\$), as recommended in the literature (Stevenson and Wolfers 2008), and Gini coefficient. Similar analyses were carried out using logistic regression for binary outcome variable high/low life satisfaction, using the Markov chain Monte Carlo method in MLwiN and fixed and random parameter estimates were tabulated. Wald tests were carried out to identify significance of parameter estimates. The test for the between-country slope variation is a simultaneous test on the slope variance and the intercept-slope covariance. Estimates reported in the results are based on a chain of length of 150,000 following a burn-in of 50,000 for models 1-3 and a chain length of 300,000 following a burn-in of 200,000 for models 4 and 5. The Deviance Information Criterion (DIC) was used as a measure of model fit with a lower value of the DIC being favoured (Spiegelhalter et al. 2002).

\section{Results}

The average age of children surveyed was approximately 13.6 years with an average age range of just over 13 to almost 14 across all countries. Across all countries, $74 \%$ of children lived with both parents, $9 \%$ in a step family, $16 \%$ in a lone parent family and $1 \%$ in another family type. However, family structure prevalence differed across countries, from almost half of children living in families other than both parent in USA to only $7 \%$ in TYFR Macedonia. There was a significant gender differences in life satisfaction; girls had a lower score on average (7.42) than boys (7.67) $(t=14.32, p<0.001)$ and a lower proportion with high life satisfaction $(82.5 \%)$ than boys $(87.2 \%)\left(\chi^{2}=249.20, p<0.001\right)$.

Table 1 describes the large cross-national differences in mean life satisfaction score, varying between 6.55 for boys and girls living in Turkey and 8.22 for TYFR Macedonia. Similarly, $94 \%$ of young people reported high life satisfaction in Netherlands, while less than two-thirds did so in Turkey. At the aggregate country level, GDP (PPP US\$) correlated significantly and positively with mean life satisfaction $(r=0.33)$ and prevalence of high life satisfaction $(r=0.51)$, so that as national income increased, so did life satisfaction. Gini, however, had a significant inverse correlation $(r=-0.27$ and -0.40 respectively), so that life satisfaction was greater for those countries with a more even income distribution.

Small gender differences were seen in life satisfaction (Table 2); girls on average scored 0.22 less than boys. Life satisfaction was also seen to fall with age, with adolescents 
Table 1 Summary of country-level variables and aggregated life satisfaction data

\begin{tabular}{|c|c|c|c|c|c|}
\hline Country & $\mathrm{N}$ & $\begin{array}{l}\text { Gini } \\
\text { coefficient }^{\dagger}\end{array}$ & $\begin{array}{l}\text { GDP (PPP US\$) } \\
\text { per capita }^{\dagger}\end{array}$ & $\begin{array}{l}\text { Average life } \\
\text { satisfaction score }\end{array}$ & $\begin{array}{l}\% \text { with high life } \\
\text { satisfaction }\end{array}$ \\
\hline Turkey & 1,564 & 0.44 & 8,407 & 6.55 & 65.7 \\
\hline Latvia & 1,397 & 0.38 & 13,646 & 6.91 & 78.9 \\
\hline Germany & 2,315 & 0.28 & 29,461 & 7.26 & 81.1 \\
\hline Russian Federation & 2,264 & 0.40 & 10,845 & 7.26 & 78.6 \\
\hline Czech Republic & 1,562 & 0.25 & 20,538 & 7.26 & 81.8 \\
\hline Ukraine & 1,616 & 0.28 & 6,848 & 7.27 & 81.7 \\
\hline Lithuania & 1,855 & 0.36 & 14,494 & 7.27 & 79.7 \\
\hline Croatia & 1,629 & 0.29 & 13,042 & 7.28 & 80.0 \\
\hline Poland & 1,604 & 0.35 & 13,847 & 7.29 & 81.1 \\
\hline Hungary & 1,158 & 0.27 & 17,887 & 7.35 & 83.9 \\
\hline Canada & 1,931 & 0.33 & 33,375 & 7.37 & 84.0 \\
\hline USA & 1,482 & 0.41 & 41,890 & 7.42 & 82.8 \\
\hline England & 1,504 & 0.36 & 33,552 & 7.44 & 84.2 \\
\hline Bulgaria & 1,495 & 0.29 & 9,032 & 7.45 & 81.1 \\
\hline Portugal & 1,184 & 0.39 & 20,410 & 7.45 & 84.0 \\
\hline France & 2,308 & 0.33 & 30,386 & 7.46 & 85.0 \\
\hline Slovenia & 1,734 & 0.28 & 22,273 & 7.47 & 85.8 \\
\hline Scotland & 2,060 & 0.31 & 29,623 & 7.48 & 84.6 \\
\hline Luxembourg & 1,416 & 0.26 & 60,228 & 7.49 & 85.0 \\
\hline Italy & 1,293 & 0.36 & 28,529 & 7.54 & 83.8 \\
\hline Estonia & 1,418 & 0.36 & 15,478 & 7.60 & 86.2 \\
\hline Sweden & 1,302 & 0.25 & 32,525 & 7.60 & 85.9 \\
\hline Belgium (Flemish) & 1,247 & 0.33 & 32,119 & 7.71 & 91.1 \\
\hline Iceland & 3,609 & 0.25 & 36,510 & 7.71 & 88.6 \\
\hline Austria & 1,455 & 0.29 & 33,700 & 7.71 & 87.1 \\
\hline Denmark & 1,714 & 0.25 & 33,973 & 7.72 & 90.6 \\
\hline Switzerland & 1,505 & 0.34 & 35,633 & 7.77 & 88.3 \\
\hline Ireland & 1,539 & 0.34 & 38,505 & 7.77 & 88.9 \\
\hline Norway & 1,416 & 0.26 & 41,420 & 7.85 & 88.1 \\
\hline Greece & 1,140 & 0.34 & 23,381 & 7.85 & 89.1 \\
\hline Spain & 2,667 & 0.35 & 27,169 & 7.88 & 90.8 \\
\hline Romania & 1,210 & 0.31 & 9,060 & 7.88 & 82.6 \\
\hline Finland & 1,648 & 0.27 & 32,153 & 7.92 & 91.8 \\
\hline Netherlands & 1,450 & 0.31 & 32,684 & 7.96 & 94.3 \\
\hline Macedonia TYFR & 1,673 & 0.39 & 7,200 & 8.22 & 88.6 \\
\hline Total average & 58,364 & 0.32 & 25,424 & 7.52 & 84.8 \\
\hline
\end{tabular}

$\dagger$ Source: For all countries 2005 GDP (PPP US\$) data from the 2007/2008 Human Development Report (HDR) are listed, and for all countries with the exception of Iceland, Luxembourg and Scotland Gini coefficient data from the 2007/2008 HDR are listed. The majority of Gini coefficient data are from surveys conducted between 2000 and 2003. Gini coefficients for Iceland and Luxembourg are from the 2005 HDR. Statistics for Scotland were obtained from the Scottish Government. English figures were converted from UK 2007/2008 HDR statistics, factoring out the figures for Scotland 


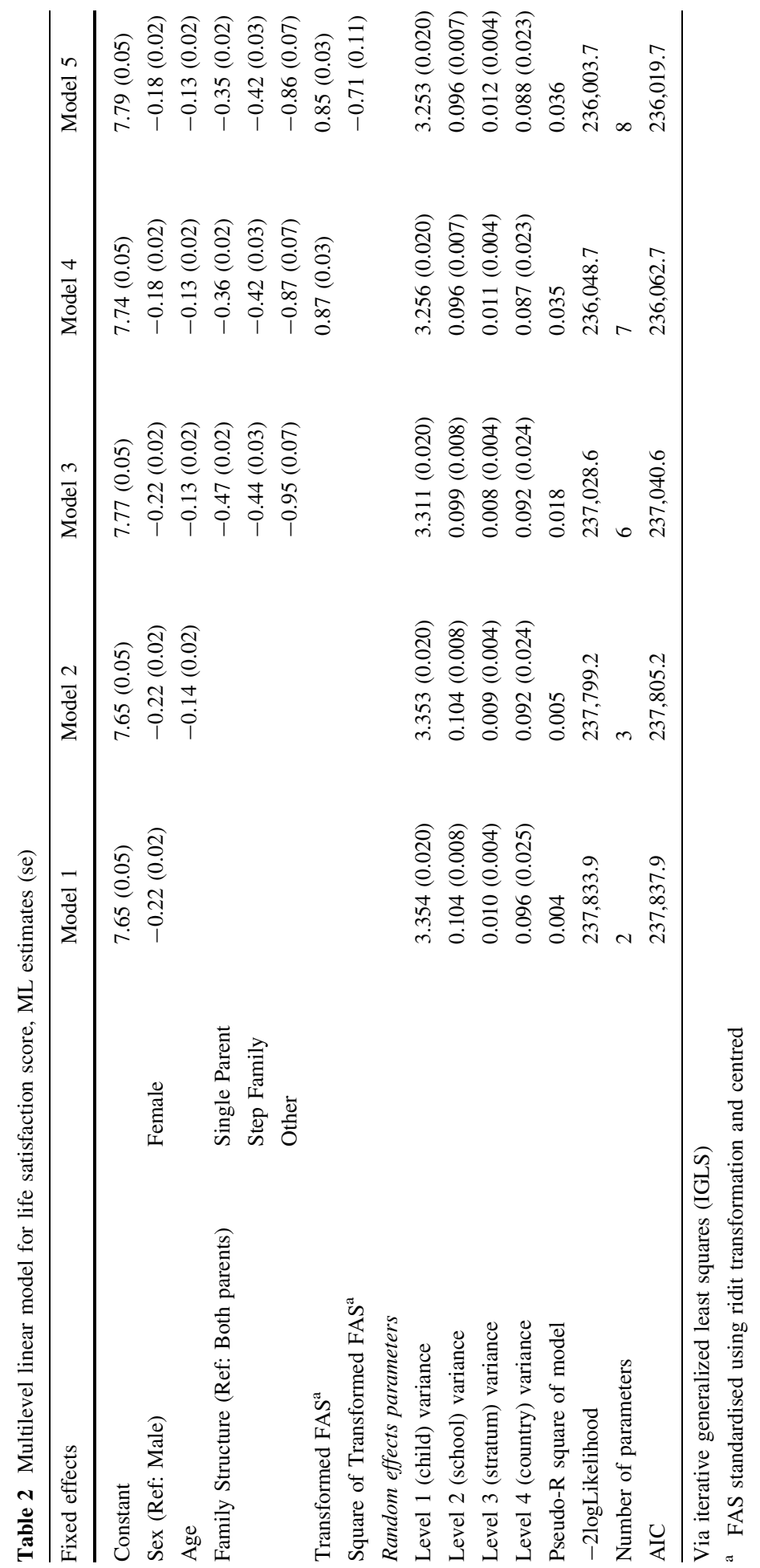


scoring on average 0.14 less than those a year their junior. Life satisfaction was highest for those in both parent families and lowest for those living in family structures described as 'other'. Within-country socioeconomic inequalities in FAS were significant, with greater life satisfaction as transformed FAS increased (Table 2, Model 4). The quadratic term was negative and significant (Table 2, Model 5), suggesting a curvilinear relationship between transformed FAS and life satisfaction so that as family affluence rose, the gradient of inequality of life satisfaction became less steep. After adjustment for family affluence, the relationship between family structure and life satisfaction remained, with only a small reduction in effect size for those in single parent families compared with those in both parent families (Table 2, Model 4). The greatest portion of variance was explained by transformed FAS, however, this still amounted to a very small proportion.

The significant between-country variance indicates significant between-country differences in average life satisfaction, even after adjustment for age, family structure, transformed FAS and FAS squared (Table 3, Model 1). The gradient of socioeconomic inequality in life satisfaction also differed significantly between countries, evidenced by the significant variance coefficient for transformed FAS (random slope).

This is also depicted in Fig. 1, which shows that the marginal effect of FAS on the continuous response, life satisfaction varies with country. The Figure suggests that countries differ more with respect to the average level of life satisfaction (the random intercepts), while the slope differences seem to be less relevant. Nevertheless, Ukraine, France and Denmark had a relatively shallow relationship between family affluence and life satisfaction, while Romania, USA, Turkey, Macedonia, Lithuania and Estonia had a particularly steep relationship. In Turkey, the line which lies nearest the bottom of the figure, children from relatively affluent backgrounds reported life satisfaction equivalent to or lower than that of relatively poor children of other countries. Though not shown in the figure or table (for ease of interpretation of coefficients) an interaction term between sex and transformed FAS shows that girls had a significantly steeper association between family affluence and life satisfaction, when compared with boys.

There was no significant association between national income (GDP (PPP US\$)) or income inequality (Gini) and young peoples' life satisfaction, over and above individual affluence (Table 3, Models 2 and 3). However, when an interaction term between transformed FAS score and GDP (PPP US\$) was added this was significant and negative (Table 3, Model 5), indicating that higher FAS had a lower impact on life satisfaction in high income compared with low income countries. Similarly, the interaction between Gini and FAS was significant and positive (Table 3, Model 4). This suggests that as countries became more unequal in their income distribution, the gradient of individual-level socioeconomic inequality in life satisfaction increased. The interaction terms did not explain the between-country differences in the relationship between individual-level life satisfaction and family affluence, as the between-country variance remained significant.

Table 4 presents the odds ratios for logit models for the binary outcome measure high/ low life satisfaction. There was a curvilinear relationship between the odds of high life satisfaction and transformed FAS. Unlike for the continuous measure of life satisfaction, both GDP (PPP US\$) and Gini were significantly associated with high life satisfaction over and above individual level FAS, with GDP (PPP US\$) explaining a greater portion of the variance than Gini. However, when an interaction term between FAS and Gini was added (Model 4), the Gini coefficient became insignificant. The interaction between GDP (PPP US\$) and FAS was less than 1 and significant, suggesting that higher family affluence raised the odds of high life satisfaction further in poorer compared with wealthier countries. The interaction term between Gini and FAS was significant and greater than 1, 


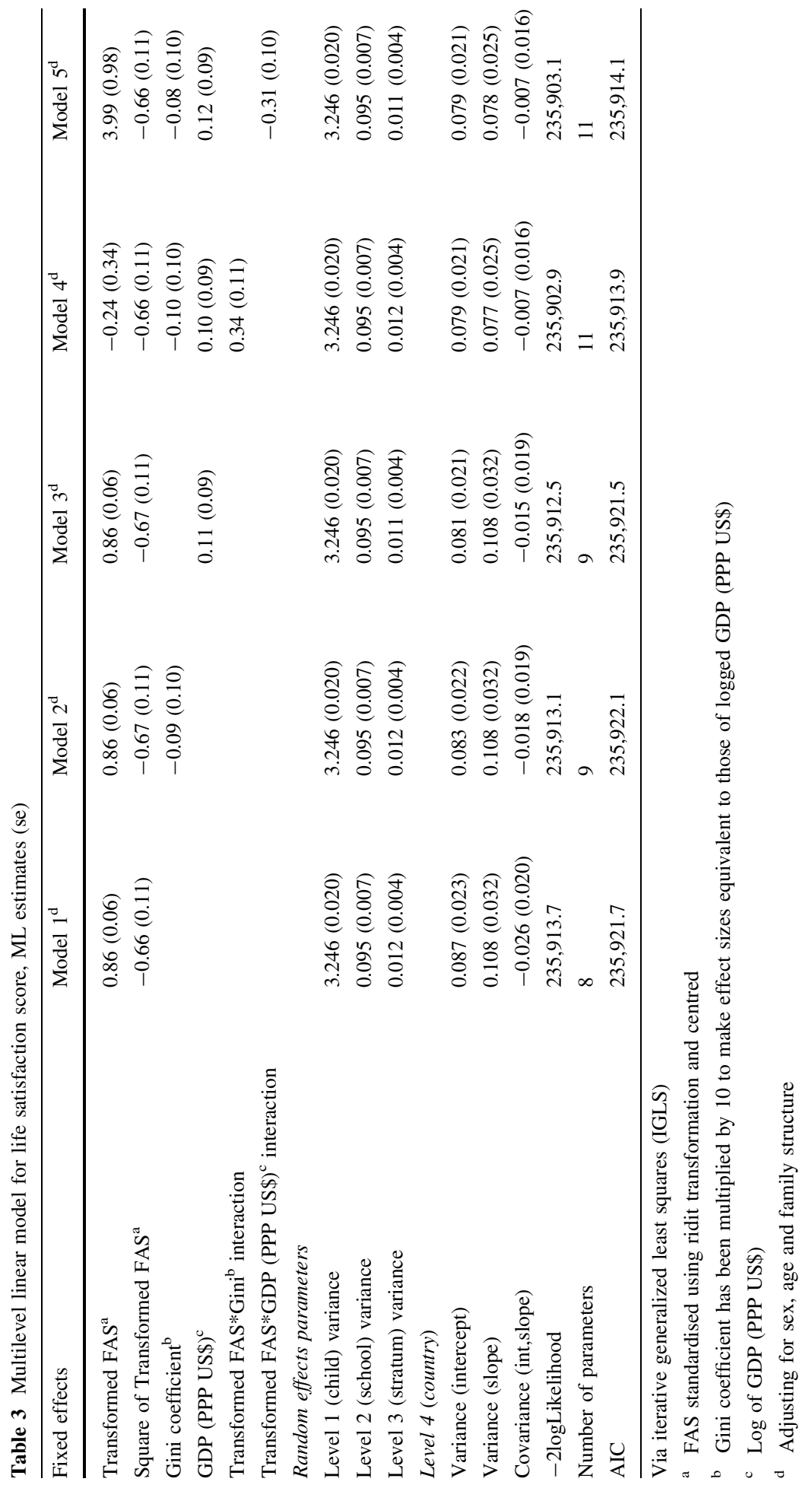




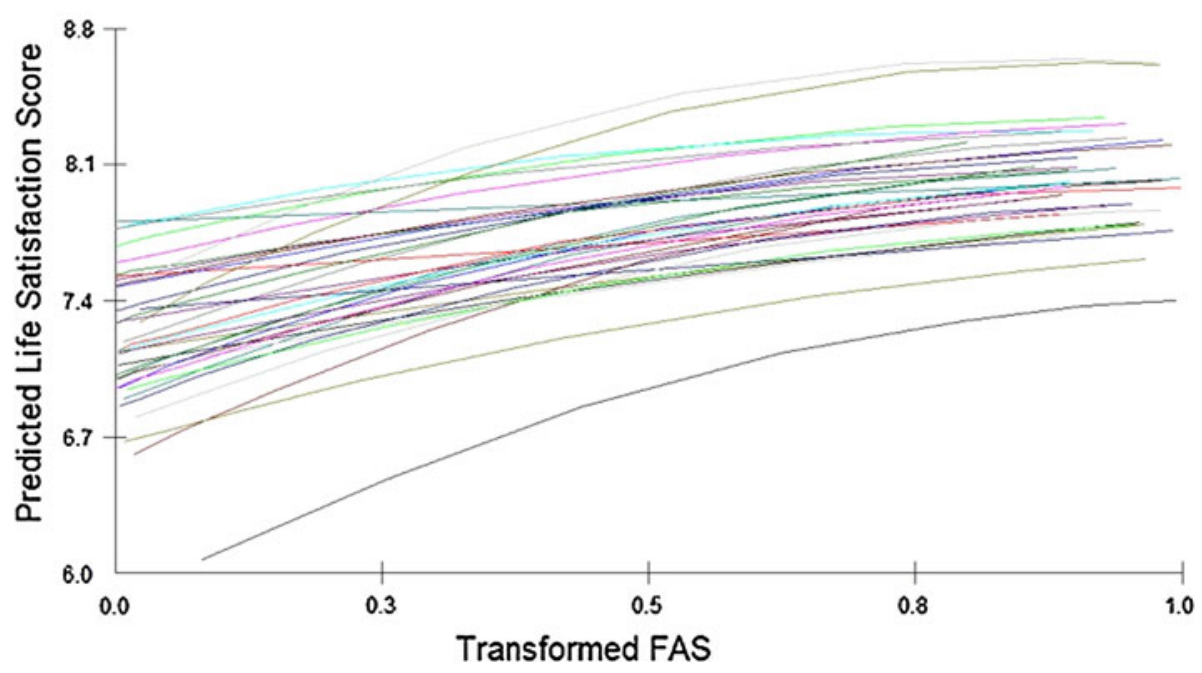

Fig. 1 Random slope model of transformed FAS and predicted life satisfaction score with separate lines for each country: Fixed and random effects for this model are presented in Table 3 (Model 1)

indicating that family affluence had a bigger impact on life satisfaction in countries with unequal income distribution. The between-country variance reduced considerably on addition of this interaction, therefore the interaction explained much of the betweencountry differences in the relationship between high life satisfaction and family affluence. The unexplained variance at the country level remained significant in all linear and logistic models (Tables 3 and 4). Unexplained variance was also significant at the stratum, school and child levels for all models in Tables 2 and 3 and at the school level for all models in Table 4 (NB for the logit models the child level variance is fixed due to identification constraints). The covariance at the country level between the random intercept and slope was not significant in any of the models.

\section{Discussion}

Life course studies have found that socioeconomic inequalities in adult health do not arise in adulthood but accumulate over time (Power and Matthews 1997). Adolescence is a critical period in human development where many patterns of health and health behaviour are formed (Bartley et al. 1997). Although many studies have examined cross-national variation in adult life satisfaction and socioeconomic inequalities in life satisfaction, to date none have looked at inequalities in adolescent life satisfaction.

This study attempted to answer four questions about the life satisfaction of young people. The first was to examine the association between national income and income distribution with life satisfaction. At the aggregate country level, associations were strong and significant, stronger for GDP (PPP US\$) than Gini. As national income increased, mean life satisfaction and prevalence of high life satisfaction rose, while countries with a less equal income distribution had lower life satisfaction outcomes. However, when examined at the individual level, the effect of both GINI and GDP on an individual's life satisfaction depended on their FAS. 


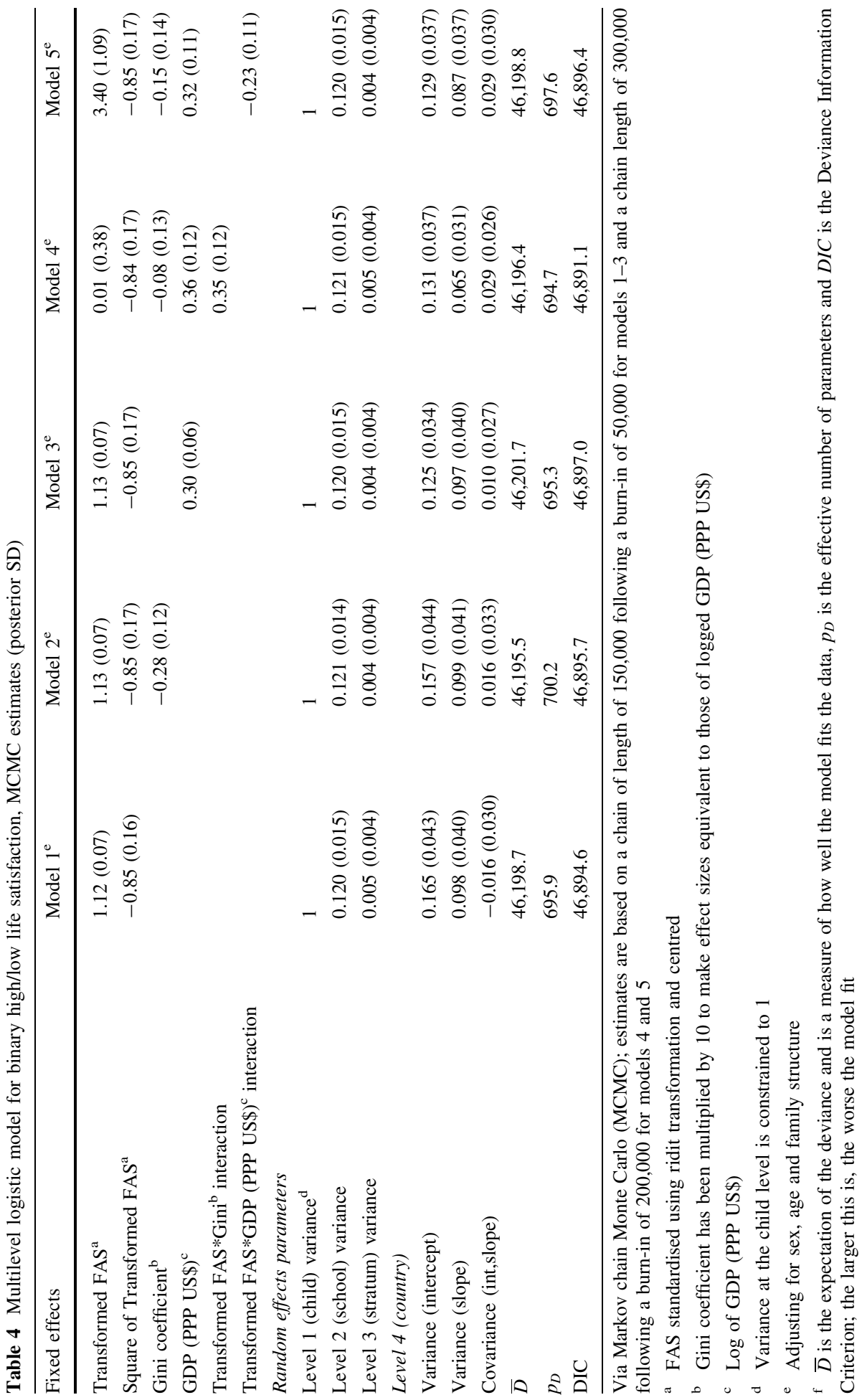


The second aim of the study was to establish if, after adjustment for family structure, individual level family affluence was related to life satisfaction. Family affluence was significantly associated with life satisfaction even after adjustment for family structure and was a more important predictor of life satisfaction than family structure, explaining more of the variance. This relationship was curvilinear, with a steeper relationship between lower FAS and life satisfaction, flattening as FAS increased. Although there is a considerable body of literature documenting gender inequalities in adult health, studies of life satisfaction and subjective well-being in general report small or no gender differences (Diener et al. 1999; Schyns 2002). The current study found that, similarly, among adolescents, gender differences in life satisfaction were small, on average 0.22 , smaller than those found for other mental health outcomes such as anxiety and depression. Gender has however a moderating effect in the relationship between adult life satisfaction and income (see Diener and Biswas-Diener 2002 for a discussion) and this was also observed among adolescents with family affluence and life satisfaction having a steeper relationship for girls than boys.

The study then examined if there was cross-national variation in the relationship between family affluence and life satisfaction, and the effect of national income and income distribution on this variation. The results showed that within-country socioeconomic inequalities in life satisfaction did significantly differ between countries. Crossnational variation in life satisfaction also remained significant after adjustment for national income and distribution of income. Higher relative affluence at the individual level, however, had more of an impact on life satisfaction in poorer countries, in line with previous findings among adults (Diener and Biswas-Diener 2002; Schyns 2002). The relationship between family affluence and life satisfaction was also steeper in those countries that had a more unequal income distribution.

There are several possible mediators of the relationship between family affluence and life satisfaction. Family structure confounds the relationship as some family structures are more likely to result in poverty. Even after controlling for family structure in the current study, the relationship between life satisfaction and family affluence persists. Previous discussions of possible mechanisms linking SES to adolescent physical and mental health can be found in the literature (Chen et al. 2002; Currie et al. 2008b; Evans 2004). These list other components related to the family context, including inconsistent parenting and strained family relationships, as well as other factors such as the school context, peer relationships, neighbourhood effects and other environmental factors, as well as risk and health behaviours, such as cigarette smoking, physical exercise and diet. One or more of these factors could mediate the relationship between life satisfaction and family affluence, or there may be a cumulative mediating effect where multiple risk factors are present. The existence and mediating influence of these factors is likely to differ cross-nationally.

The impact of having low family affluence on life satisfaction might be minimised through identification of within-and across-country mediating factors, particularly in countries with low national income and unequal income distribution, and the creation of appropriate health promotion policies. This may also be easier to achieve than- or complementary to- attempting to raise individual household affluence by augmenting household income through social policies, such as minimum wage and welfare benefits or progressive taxation. Future work is recommended to examine potential mediators, such as those described above.

Previous cross-national studies examining adult well-being found that cultural and societal factors are as, if not more, important in explaining international differences, 
particularly among developed countries of similar income (Schyns 2002; Veenhoven 1991; West 1997). This is also likely to be true for adolescents. Within the current study there is clear evidence that between-country variation persists even after adjustment for economic factors. Cultural values, such as individualism, humanitarianism, materialism, competition, avoidance of failure and ideology may explain, directly or indirectly through parental behaviour, some of the cross-national variance in young people's life satisfaction and in the relationship between life satisfaction and FAS. Future research which includes national cultural and societal factors such as those listed above is recommended.

\subsection{Limitations}

Despite widespread use, the individual items in FAS and in other similar measures of social status (e.g. the Carstairs Index), may be prone to bias. For example, car ownership varies according to availability of public transport and urban/rural location; having one's own room reflects the size of one's house, the demography of the household and urban/rural living; and computer ownership and family holidays may vary according to family demography. A preferred measure of SES would be household income. In household based studies where adult members are included in the survey this may be possible. However, the HBSC survey is a school-based survey completed by adolescents who are unlikely to know their parents' income.

\section{Conclusions}

This study shows a relationship between family affluence and life satisfaction across several countries, with the strength of relationship varying by country. While Romania, USA, Turkey, Macedonia, Lithuania and Estonia had a relatively steep relationship, Denmark, Ukraine and France had a relatively shallow relationship. The existence of, and variation in, within-country socioeconomic inequalities in adolescent life satisfaction, adds to the life course literature that highlights the importance of life stages in the study of health. The findings reported fill an important gap in the economics of well-being literature, showing patterns of association at a younger age group similar to those in adulthood, which suggest a relatively early life effect of individual (household) level affluence on life satisfaction, dependent on national income and income distribution. Adolescence is a time characterised by the reduction in life satisfaction (Goldbeck et al. 2007). It is also a time when trajectories for adult life may be set. This is therefore an early life stage where interventions could be effectively targeted with results potentially lasting into adulthood, particularly directed at least affluent young people in poor countries and countries with less equal income distribution.

Acknowledgments The Health Behaviour in School-aged Children (HBSC) study is an international survey conducted in collaboration with the WHO Regional Office for Europe. The authors would like to acknowledge the HBSC international research network in 43 countries that developed the study's research protocol. The authors would also like to thank Stephen Donnelly for his help with the graphics. This study was funded by NHS Health Scotland.

Open Access This article is distributed under the terms of the Creative Commons Attribution Noncommercial License which permits any noncommercial use, distribution, and reproduction in any medium, provided the original author(s) and source are credited. 


\section{References}

Ash, C., \& Huebner, E. S. (2001). Environmental events and life satisfaction reports of adolescents- a test of cognitive mediation. School Psychology International, 3, 320-336.

Attar, B. K., Guerra, N. G., \& Tolan, P. H. (1994). Neighbourhood disadvantage, stressful life events, and adjustment in urban elementary school children. Journal of Clinical Child Psychology, 23, 391-400.

Bartley, M., Blane, D., \& Montgomery, S. (1997). Socioeconomic determinants of health: Health and the life course: Why safety nets matter. British Medical Journal, 314, 1194-1196.

Burton, P., \& Phipps, S. (2008). Economic resources, relative socioeconomic position and social relationships: Correlates of the happiness of young Canadian teens. Child Indicators Research, 1, 350-371.

Cantril, H. (1965). The pattern of human concerns. New Brunswick, NJ: Rutgers University Press.

Chen, E., Langer, D. A., Raphaelson, Y. E., \& Matthews, K. A. (2004). Socioeconomic status and health in adolescents: The role of stress interpretations. Child Development, 75, 1039-1052.

Chen, E., Martin, A. D., \& Matthews, K. A. (2006). Socioeconomic status and health: Do gradients differ within childhood and adolescence? Social Science and Medicine, 62, 2161-2170.

Chen, E., Matthews, K. A., \& Boyce, W. T. (2002). Socioeconomic differences in children's health: How and why do these relationships change with age. Psychological Bulletin, 128, 295-329.

Currie, C. E., Elton, R. A., Todd, J., \& Platt, S. (1997). Indicators of socioeconomic status for adolescents: The WHO Health Behaviour in School-aged Children Survey. Health Education Research, 12, 385-397.

Currie, C., Molcho, M., Boyce, W., Holstein, B., Torsheim, T., \& Richter, M. (2008a). Researching health inequalities in adolescents: The development of the Health Behaviour in School-aged Children (HBSC) Family Affluence Scale. Social Science and Medicine, 66, 1429-1436.

Currie, C., Nic Gabhainn, S., Godeau, E., et al. (2008b). Inequalities in young people's health: Health Behaviour in School-aged Children International Report from the 2005/2006 Survey. Copenhagen: WHO Europe.

Di Tella, R., MacCulloch, R. J., \& Oswald, A. J. (2003). The macroeconomics of happiness. The Review of Economics and Statistics, 85, 809-827.

Diener, E., \& Biswas-Diener, R. (2002). Will money increase subjective well-being? Social Indicators Research, 57, 119-169.

Diener, E., Diener, M., \& Diener, C. (1995). Factors predicting the subjective well-being of nations. Journal of Personality and Social Psychology, 69, 851-864.

Diener, E., Suh, E. M., Lucas, R. E., \& Smith, H. L. (1999). Subjective well-being: Three decades of progress. Psychological Bulletin, 125, 276-302.

Easterlin, R. A. (1974). Does economic growth improve the human lot?: Some empirical evidence. In P. A. David \& W. R. Melvin (Eds.), Nations and households in economic growth (pp. 98-125). Palo alto, CA: Stanford University Press.

Emerson, E., Graham, H., \& Hatton, C. (2006). Household income and health status in children and adolescents in Britain. European Journal of Public Health, 16, 354-360.

Evans, G. W. (2004). The environment of childhood poverty. American Psychologist, 59, 77-92.

Goldbeck, L., Schmitz, T. G., Besier, T., Herschbach, P., \& Henrich, G. (2007). Life satisfaction decreases during adolescence. Quality of Life Research, 16, 969-979.

Goodman, E. (1999). The role of socioeconomic status gradients in examining differences in US adolescents' health. American Journal of Public Health, 89, 1522-1528.

Gump, B. B., Matthews, K. A., \& Raikkonen, K. (1999). Modelling relationships among socioeconomic status, hostility, cardiovascular reactivity and left ventricular mass in African American and White children. Health Psychology, 18, 140-150.

Helliwell, J. F. (2007). Well-being and social capital: Does suicide pose a puzzle? Social Indicators Research, 81, 455-496.

Herman, H., Saxena, S., \& Moodie, R. (2005). Promoting mental health: Concepts, emerging evidence, practice. Geneva: WHO Europe (pp. XVIII).

Keyes, C. L. M. (2006). Mental health in adolescence: Is America's youth flourishing? The American Journal of Orthopsychiatry, 76, 395-402.

Koivumaa-Honkanen, H., Honkanen, R., Viinamaki, H., Heikkila, K., Kaprio, J., \& Koskenvuo, M. (2001). Life satisfaction and suicide: A 20-year follow-up study. The American Journal of Psychiatry, 158, 433-439.

Koivumaa-Honkanen, H. T., Kaprio, J., Honkanen, R., Viinamaki, H., \& Koskenvuo, M. (2004). Life satisfaction and depression in a 15-year follow-up of healthy adults. Social Psychiatry and Psychiatric Epidemiology, 39, 994-999. 
Lien, N., Friestad, C., \& Klepp, K. I. (2001). Adolescents' proxy reports of parents' socioeconomic status: How valid are they? Journal of Epidemiology and Community Health, 55, 731-737.

Manor, O., Matthews, S., \& Power, C. (1997). Comparing measures of health inequality. Social Science and Medicine, 45, 761-771.

Maslow, A. H. (1970). Motivation and personality. New York: Harper \& Row. (pp. 67).

Oishi, S., Diener, E. F., Lucas, R. E., \& Suh, E. M. (1999a). Cross-cultural variations in predictors of life satisfaction: Perspectives from needs and values. Personality and Social Psychology Bulletin, 25, 980-990.

Oishi, S., Diener, E., Suh, E., \& Lucas, R. E. (1999b). Value as a moderator in subjective well-being. Journal of Personality, 67, 157-184.

Power, C., \& Matthews, S. (1997). Origins of health inequalities in a national population sample. Lancet, $350,1584-1589$.

Rasbash, J., Steele, F., Browne, W., \& Prosser, B. (2004). A user's guide to MLwiN: Version 2.0. London: University of London.

Repetti, R. L., Taylor, S. E., \& Seeman, T. E. (2002). Risky families: Family social environments and the mental and physical health of offspring. Psychological Bulletin, 128, 330-366.

Schyns, P. (2002). Wealth of nations, individual income and life satisfaction in 42 countries: A multilevel approach. Social Indicators Research, 60, 5-40.

Scottish Executive (2006). Measuring progress towards a smart, successful Scotland: 2006. Edinburgh: Scottish Executive. Retrieved July 6, 2009, from http://www.scotland.gov.uk/Publications/2006/ 12/19161336/0.

Scottish Executive (2007). Scottish Economic Statistics 2007. Edinburgh: Scottish Executive. Retrieved July 6, 2009, from http://www.scotland.gov.uk/Publications/2007/07/18083820/4.

Spencer, N. J. (2006). Social equalization in youth: Evidence from a cross-sectional British survey. European Journal of Public Health, 16, 368-375.

Spiegelhalter, D. J., Best, N. G., Carlin, B. P., \& van der Linde, A. (2002). Bayesian measures of model complexity and fit (with discussion). Journal of the Royal Statistical Society, Series B (Statistical Methodology), 64(4), 583-639.

Starfield, B., Riley, A. W., Witt, W. P., \& Robertson, J. (2002). Social class gradients in health during adolescence. Journal of Epidemiology and Community Health, 56, 354-361.

Stevenson, B., \& Wolfers, J. (2008). Economic growth and subjective well-being: Reassessing the Easterlin Paradox. Paper presented at 85th Conference of the Brookings Panel on Economic Activity, Washington DC.

Torsheim, T., Currie, C., Boyce, W., Kalnins, I., Overpeck, M., \& Haugland, S. (2004). Material deprivation and self-rated health: A multilevel study of adolescents from 22 European and North American countries. Social Science and Medicine, 59, 1-12.

Torsheim, T., Currie, C., Boyce, W., \& Samdal, O. (2006). Country material distribution and adolescents' perceived health: Multilevel study of adolescents in 27 countries. Journal of Epidemiology and Community Health, 60, 156-161.

United Nations Development Programme. (UNDP). (2005). Human Development Report 2005: International cooperation at the crossroads. Aid, trade and security in an unequal world. New York: Palgrave Macmillan. Retrieved July 6, 2009, from http://hdr.undp.org/en/media/HDR05_complete.pdf.

United Nations Development Programme (UNDP). (2008). Human Development Report 2007/2008: Fighting climate change: Human solidarity in a divided world. New York: Palgrave Macmillan. Retrieved July 6, 2009, from http://hdr.undp.org/en/media/HDR_20072008_EN_Complete.pdf.

Veenhoven, R. (1991). Is happiness relative? Social Indicators Research, 24, 1-34.

Wardle, J., Robb, K., \& Johnson, F. (2002). Assessing socioeconomic status in adolescents: The validity of a home affluence scale. Journal of Epidemiology and Community Health, 56, 595-599.

Wardle, J., Robb, K. A., Johnson, F., Griffith, J., Power, C., \& Brummer, E., et al. (2004). Socioeconomic variation in attitudes to eating and weight in female adolescents. Health Psychology, 23(3), 275-282.

West, P. (1997). Health inequalities in the early years: Is there equalisation in youth? Social Science and Medicine, 44, 833-885. 